\title{
Woodceramic Heating Elements for Low Temperature Heating
}

\author{
Junichiro Tsuji ${ }^{1}$, Riko Ozao ${ }^{2}$, Toshihiro Okabe ${ }^{3}$, Toshikazu Suda ${ }^{4}$ and Ryoichi Yamamoto ${ }^{5}$ \\ ${ }^{1}$ Polytechnic Center Gunma, Takasaki, Gunma 370-1213, Japan \\ ${ }^{2}$ SONY Institute of Higher Education, Atsugi 243-8501, Japan \\ ${ }^{3}$ Industrial Research Institute of Aomori Prefecture, Aomori 030-0113, Japan \\ ${ }^{4}$ Polytechnic University, Sagamihara 229-1196, Japan \\ ${ }^{5}$ Center for Collaborative Research, University of Tokyo, Tokyo 153-8904, Japan
}

Woodceramics are carbon-carbon composites produced by impregnating plant-origin lignocellulosic materials with phenolic resin and by carbonizing the resulting precursor at temperatures higher than $650^{\circ} \mathrm{C}$. Since the electric resistance of the woodceramics changes as a function of the carbonizing temperature, heating elements for use in biological incubator systems can be prepared by controlling the electric resistance to obtain optimal Joule heat. Woodceramic heating blocks carbonized at temperatures lower than $800^{\circ} \mathrm{C}$ were found preferable from the viewpoint of lower water absorptivity. Then, woodceramic test specimens $\left(310 \times 52 \times 18 \mathrm{~mm}^{3}\right)$ were produced from medium density fiberboard (MDF) at carbonizing temperatures of $650,700,750$, and $800^{\circ} \mathrm{C}$ (which are simply denoted as $650,700,750$, and 800 , respectively). The electric resistance of the test specimens $650,700,750$, and 800 at applied voltage of $10 \mathrm{~V}$ was $50,10,8$, and $4 \Omega$, respectively. Thus, single test piece of 650,3 serially connected 700,7 serially connected 750 , and 10 serially connected 800 were used to obtain the temperature profile. Temperature rise of each test specimen was measured under applied voltages of $10,20,30$, and $40 \mathrm{~V}$. For 650 , fair temperature stability was obtained at $22^{\circ} \mathrm{C}$ $(10 \mathrm{~V})$ and $27-31^{\circ} \mathrm{C}(20 \mathrm{~V})$. The advantages of the woodceramic heaters as compared with the conventional ceramic heaters are: (1) quick rise in temperature; (2) high stability at designated temperature; (3) lower power consumption; and (4) free of air convection (heats the sample directly and homogeneously).

(Received August 17, 2005; Accepted November 8, 2005; Published December 15, 2005)

Keywords: carbon/carbon composite, woodceramics, heater element, water absorption, incubator

\section{Introduction}

Woodceramics are porous carbon/carbon composites or hybrid materials consisting of cellulose-originated carbon reinforced by glassy carbon generated from resin. They are produced by impregnating carbonaceous materials with thermo-setting resin, such as phenolic resin, and by carbonizing the resin-impregnated material in a vacuum furnace. ${ }^{1)}$ Woodceramics obtained from wood are generally porous, and have macro-pores with diameter ranging from 1 to $50 \mu \mathrm{m}$. So far, woodceramics had been produced from woodbased materials, such as hiba (Thujopsis dolabrata var. hondae), cedar (Cryptomeria japonica), pine (Pseudotsuga menziesii), MDF (medium density fiber) boards, waste paper, apple wastes, etc.

Woodceramics are superior to the original wood in thermal resistance, and because they are porous, their density is normally about $1.0 \mathrm{Mg} \mathrm{m}^{-3}$, i.e., about the same as that of epoxy resins or polyethylene resins, and about one third of that of widely used ceramics such as alumina. Physical properties of woodceramics differ depending on the starting material and sintering temperature, however, it is now well established that woodceramics based on medium-density fiberboard of satisfactory strength $(3.1 \mathrm{GPa}$ Young's Modulus, $24 \mathrm{MPa}$ fracture strength) can be obtained by sintering at $800^{\circ} \mathrm{C}$ or higher. ${ }^{2)}$

Mechanical properties of typical woodceramics obtained from medium density fiberboard (MDF) carbonized at $800^{\circ} \mathrm{C}$ are compared with other structural materials in Table $1 .{ }^{3)} \mathrm{It}$ can be understood that they are lightweight material with considerable strength, and that they are more elastic than ceramics.

In addition to the mechanical properties, woodceramics are interesting because that their resistance can be controlled by
Table 1 Mechanical Properties of woodceramics compared with other structural materials.

\begin{tabular}{llll}
\hline \multicolumn{1}{c}{ Materials } & $\begin{array}{c}\text { Density } \\
\left(\mathrm{Mg} \mathrm{m}^{-3}\right)\end{array}$ & $\begin{array}{c}\text { Young's } \\
\text { Modulus } \\
(\mathrm{GPa})\end{array}$ & $\begin{array}{c}\text { Compression } \\
\text { strength } \\
(\mathrm{MPa})\end{array}$ \\
\hline $\begin{array}{l}\text { Woodceramics (MDF800) } \\
\text { Epoxy resin }\end{array}$ & 1.0 & 3.1 & 24 \\
Polyethylene resin & $1.1-1.4$ & $1.3-4.5$ & $45-85$ \\
Graphite & 0.9 & 0.2 & $7-17$ \\
Carbon steel & 1.6 & 0.1 & 35 \\
(Low alloy steel) & 7.9 & 203 & $420-2000$ \\
Aluminum alloy (\#2000) & 2.8 & 71 & $300-600$ \\
Silicon carbide & 3.2 & 410 & 2000 \\
Zirconia & 5.6 & 200 & 2000 \\
\hline
\end{tabular}

changing the carbonizing temperature. ${ }^{4)}$ Miki et al. ${ }^{6)}$ reports that the electric resistivity of woodceramics made from MDF mixed with 33 mass\% phenolic resin considerably drops with increasing temperature; the resistivity of woodceramics obtained by carbonizing at $650^{\circ} \mathrm{C}$, which was about $10 \Omega \mathrm{cm}$, decreased to $\mathrm{ca} .5 \times 10^{-1} \Omega \mathrm{cm}$ by carbonizing at a higher temperature of $800^{\circ} \mathrm{C}$. Thus, it is expected that a heater body based on Joule heating can be fabricated by carbonizing wood-based materials at temperatures lower than $800^{\circ} \mathrm{C}$. However, local heat-up may occur attributed to the porous nature of the material, or drop in resistance with elevating temperature may lead to the occurrence of runaway effect. Furthermore, it is reported that the resistivity decreases with increasing humidity. ${ }^{5}$ )

It is also to be noted that, because woodceramics are porous, their radiant energy (wavelength) distribution is similar to that of black body. ${ }^{3)}$ Thus, woodceramic blocks are expected to provide excellent heating elements capable of 


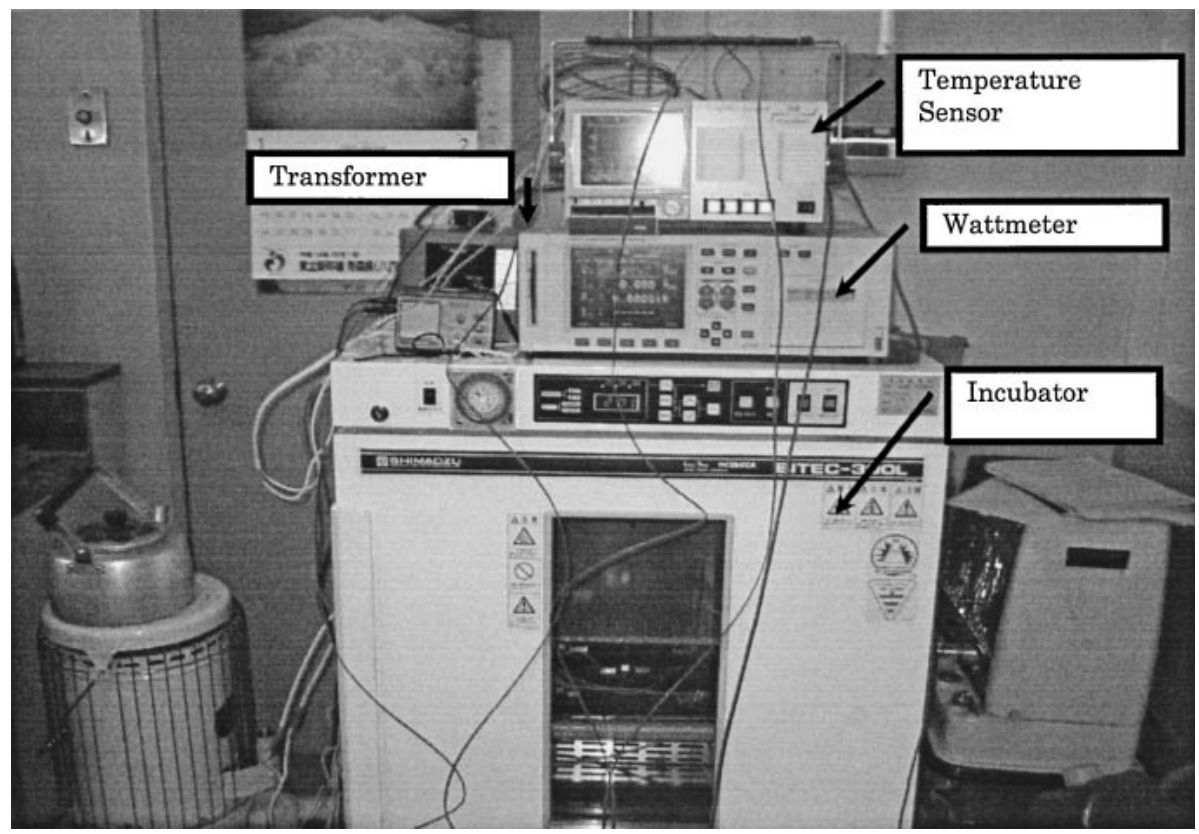

Fig. 1 Experimental setup for use in testing woodceramic heating blocks.

heating at moderate temperatures for use in, e.g., biological incubator systems. Conventional incubator systems utilize warm air heated by ceramic heating elements, and they suffered disadvantages such as (1) lack of uniform heating due to convection, (2) requiring long time for stabilization, (3) low efficiency and high power consumption, and (4) causing inhomogeneous temperature distribution in the heated object.

The present paper reports on the fabrication of heater block which functions effectively when assembled in biological incubator systems. First, carbonizing temperature range was determined by selecting heater blocks having lower water absorption, and then, the optimum heater block configuration was selected by evaluating the temperature controllability or stability.

\section{Experimental}

\subsection{Samples}

Woodceramic heating blocks $\left(310 \times 52 \times 18 \mathrm{~mm}^{3}\right)$ for evaluating water absorption characteristics were produced from medium density fiberboard (MDF) at carbonizing temperatures of $650,800,1000$, and $1200^{\circ} \mathrm{C}$.

\subsection{Experimental setup}

Figure 1 shows the experimental setup for evaluating the woodceramic heating block. It comprises an incubator, a wattmeter, temperature sensor, and a transformer. The temperature inside the incubator was set constant to $20^{\circ} \mathrm{C}$.

\subsection{Optimization of heater block configuration}

The electric resistance of the test specimens 650, 700, 750, and 800 at applied voltage of $10 \mathrm{~V}$ was $50,10,8$, and $4 \Omega$, respectively. Similar results were obtained for other applied voltages (See Fig. 2). Thus, in order to set the electric resistance equivalent for all of the heating blocks, the test specimens were serially connected; i.e., 3 blocks of 700 were

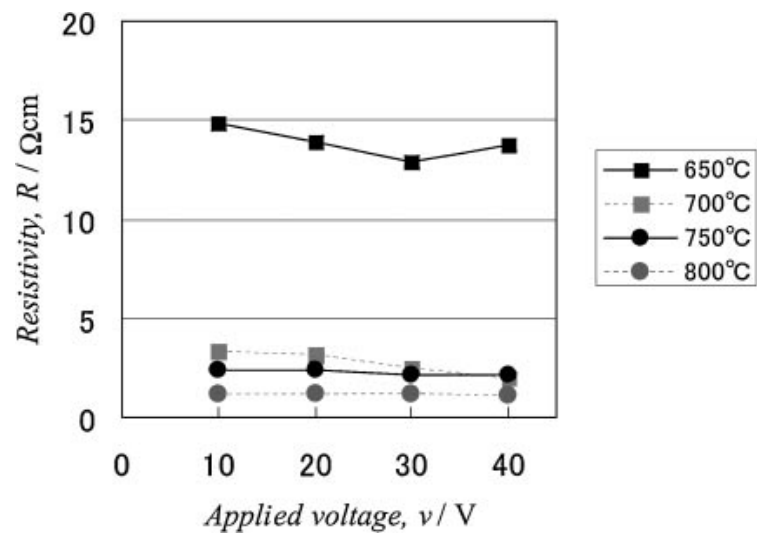

Fig. 2 Electrical resistivity under different applied voltage for the woodceramic heating block samples carbonized at different temperatures.

serial connected (See Fig. 3), 7 blocks for 750, and 10 blocks for 800 .

\subsection{Temperature Change with Time}

In order to evaluate optimum Joule heat generation, surface temperature of the heating block was measured while changing the applied voltage to $10,20,30$, and $40 \mathrm{~V}$. To assure uniform heating, the temperature was measured at 5 different points. In Fig. 4 is shown the measuring positions for 650 and 700. Change in temperature was also measured inside the incubator.

\section{Results and Discussion}

\subsection{Sample characterization}

Figure 5 shows the volume $\left(\mathrm{cm}^{3}\right)$, bone-dry weight $(\mathrm{g})$, and the weight $(\mathrm{g})$ after immersing the bone-dried heating blocks in water for $5 \mathrm{~h}$ (denoted as "Wet weight", hereinafter), of the sample blocks. Figure 6 shows the density of the 


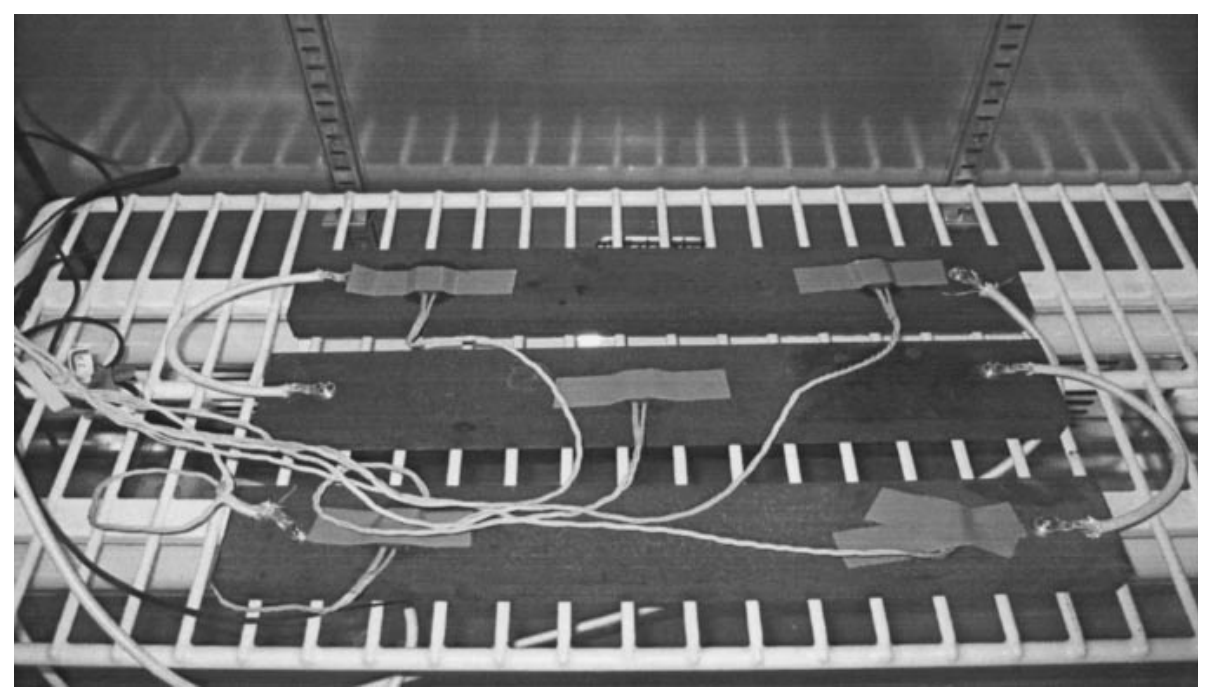

Fig. 3 Serial connected three blocks of test specimen 700 .

\section{Sample 650 Sample 700}

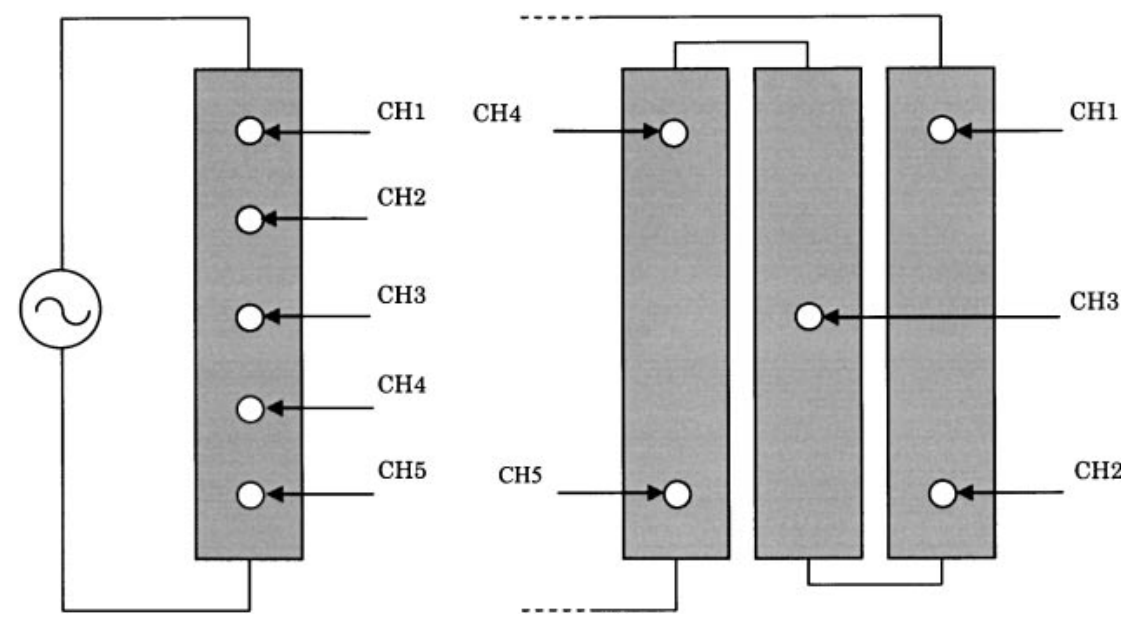

Fig. 4 Temperature measuring points for samples 650 and 700 .

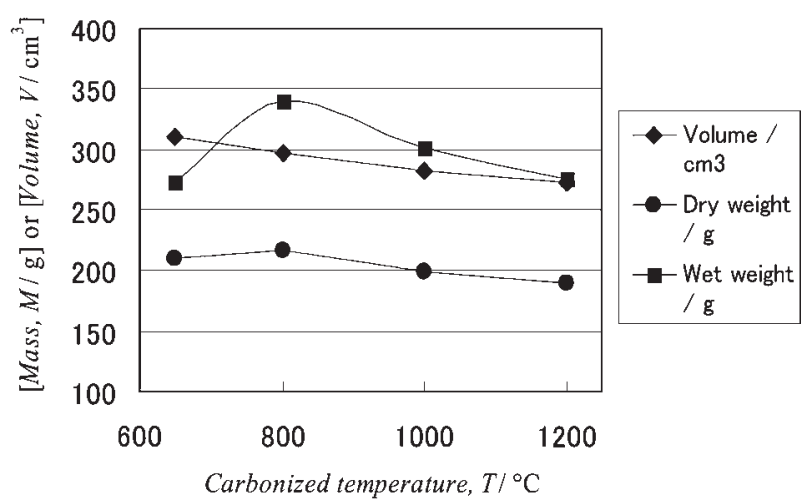

Fig. 5 Volume, bone-dry weight, and weight after immersing in water for $5 \mathrm{~h}$ of the samples obtained by carbonizing at $650,800,1000$, and $1200^{\circ} \mathrm{C}$.

dry sample and the water absorption ratio $w$ of the samples as defined in the following equation (1), after immersing the blocks in water for $5 \mathrm{~h}$.

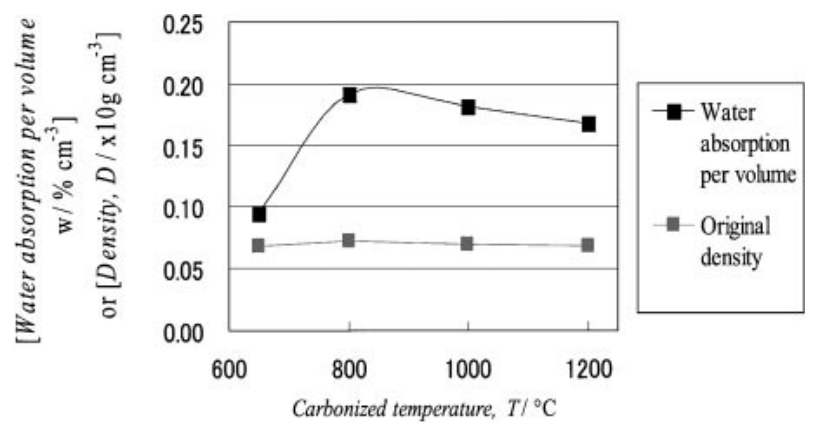

Fig. 6 Water adsorption ratio for woodceramic heater blocks obtained by carbonizing at $650,800,1000$, and $1200^{\circ} \mathrm{C}$.

$$
w=\frac{W_{\text {wet }}-W_{\text {dry }}}{W_{\text {dry }}} \frac{1}{V}
$$

where, $w$ represents the water absorption ratio per volume $\left(\mathrm{cm}^{-3}\right), W_{\text {wet }}$ represents the weight $(\mathrm{g})$ after immersing the bone-dried heating blocks in water for $5 \mathrm{~h}, W_{\text {dry }}$ represents the 
bone-dry weight $(\mathrm{g})$, and $V$ represents the volume $\left(\mathrm{cm}^{3}\right)$ of the bone-dry heating block. The results are given in Fig. 6 .

Based on the results above, woodceramics carbonized in the temperature range of $650-800^{\circ} \mathrm{C}$ have been found ideal for the heating blocks. Thus, woodceramic heating blocks $\left(310 \times 52 \times 18 \mathrm{~mm}^{3}\right)$ for obtaining the temperature profile were produced from medium density fiberboard (MDF) at carbonizing temperatures of $650,700,750$ and $800^{\circ} \mathrm{C}$ (which are denoted hereinafter as sample 650, 700, 750, and 800, respectively).

\subsection{Water absorption properties}

As described above, since electric resistivity of the heater blocks is influenced by humidity, heater blocks low in water absorption are preferred for use in incubators. As shown in Fig. 5, it can be understood that the volume and the mass slightly decreases with increasing carbonizing temperatures. This result is in good agreement with previous reports; ${ }^{7)}$ it is well established that the mass and the volume considerably decrease when heated from room temperature to $650^{\circ} \mathrm{C}$, at which condensation of aromatic polynuclear structure is fully developed from the phenolic resin and the decomposition of the original wood is mostly completed. Kercher and Nagle ${ }^{8)}$ studied the carbonization process of the medium density fiberboard alone and reported that the growth of large turbostratic crystallites ceased at temperatures higher than $600^{\circ} \mathrm{C}$, and that the graphene sheet grew substantially to cause volumetric shrinkage. They also suggest the impingement of the conductive graphene sheets causes the nonmetalmetal transition at higher temperatures. In Fig. 6 is shown the density of the woodceramic samples. Although the density for all of the samples is lower than water, samples carbonized at temperatures higher than $800^{\circ} \mathrm{C}$ sunk in the water bath after 5-h immersion. It can be therefore understood that the sample carbonized at $650^{\circ} \mathrm{C}$ only has water-repelling property, probably attributed to the remaining water-repelling wood-like properties.

It can be clearly understood from the above results that samples carbonized between 650 to $800^{\circ} \mathrm{C}$ are preferred for heater blocks from the viewpoint of water absorptivitiy, and only samples $650,700,750$, and 800 are studied hereinafter.

\subsection{Change of temperature with time (temperature profile)}

For use as heating elements of incubators, the heating elements must keep the temperature constant at the desired temperature without causing a temperature shoot inside the incubator. Figures 7(a) and (b) show the change of surface temperature for 650 and 700, respectively with passage of time (average of 5 measuring points, $\mathrm{CH} 1-\mathrm{CH} 5$ in Fig. 6). It can be seen that the heater can hold temperature at 22 or $29^{\circ} \mathrm{C}$ at applied voltage of 10 or $20 \mathrm{~V}$, but at a higher applied voltage of $30 \mathrm{~V}$, the temperature gradually increases with time, and furthermore, it takes longer time to reach a constant temperature. Moreover, temperature overshoot occurs at an applied voltage of $40 \mathrm{~V}$. Higher Joule heat generates at higher applied voltages, and the inner resistivity decreases with increasing temperature; failure in temperature control occurs in this manner. The same tendency is observed for other

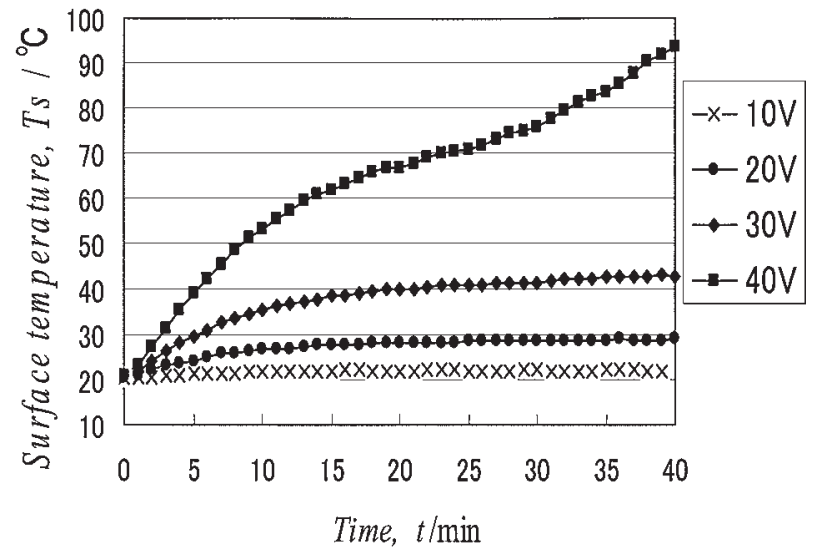

(a)

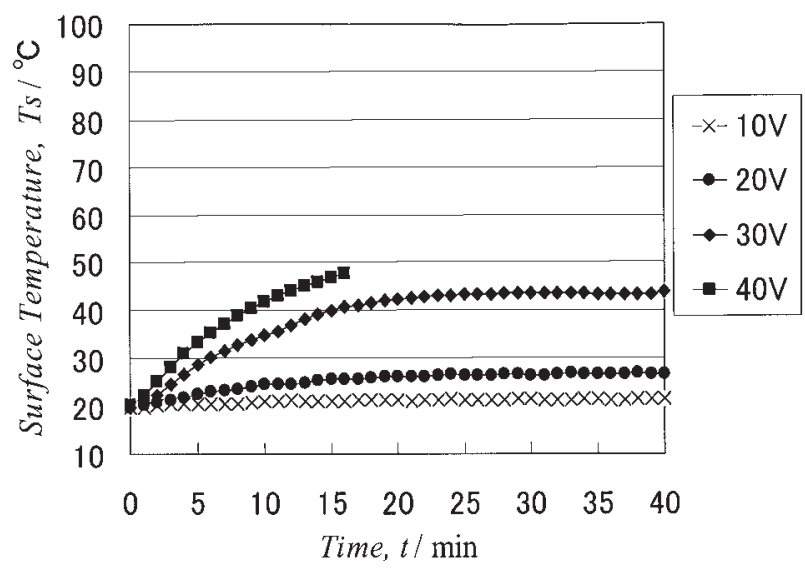

(b)

Fig. 7 Change of surface temperature with passage of time for 650 (average of 5 measuring points).

samples, but distinct temperature overshoot is found at applied voltages of 30 and $40 \mathrm{~V}$.

\subsection{Temperature distribution within the block (temper- ature stability)}

As described above, longer and more stable temperature control can be realized by using heating block 650 , and more uniform temperature distribution within the block is preferred. Figures 8(a) to (d) shows the temperature fluctuation inside a single block of 650 . It can be seen that for 650 , excellent temperature stability was obtained for applied voltage of $10 \mathrm{~V}$, because the temperature measured at 5 measuring points $(\mathrm{CH} 1-\mathrm{CH} 5)$ falls near $22^{\circ} \mathrm{C}$. At applied voltage of $20 \mathrm{~V}$, fair temperature uniformity was obtained; the temperature difference is $4^{\circ} \mathrm{C}\left(27-31^{\circ} \mathrm{C}\right)$. However, at applied voltage of $30 \mathrm{~V}$, the temperature difference amounts to $10^{\circ} \mathrm{C}\left(39-49^{\circ} \mathrm{C}\right)$ between $\mathrm{CH} 1$ and $\mathrm{CH} 5$. Under applied voltage of $40 \mathrm{~V}$, temperature overshooting occurs and is not preferred.

\subsection{Temperature vs. time profiles of the heater block and conventional ceramic heater}

Figure 9 shows the time necessary to reach temperatures between 23.8 and $33^{\circ} \mathrm{C}$ for a conventional ceramic heater (commercially available ceramic heater for heating solders) and a woodceramic heater (carbonized at $650^{\circ} \mathrm{C}$ ), both under 


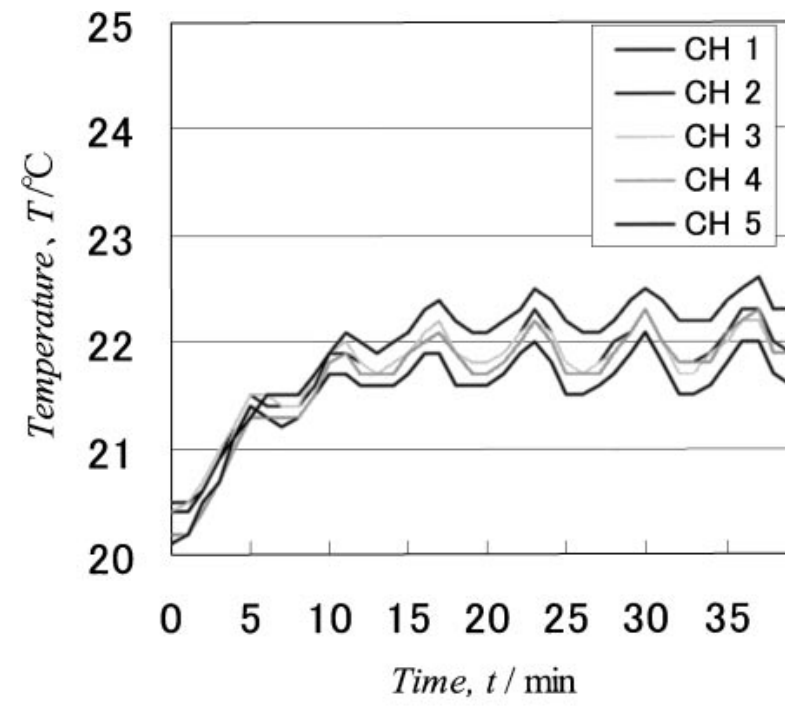

(a)

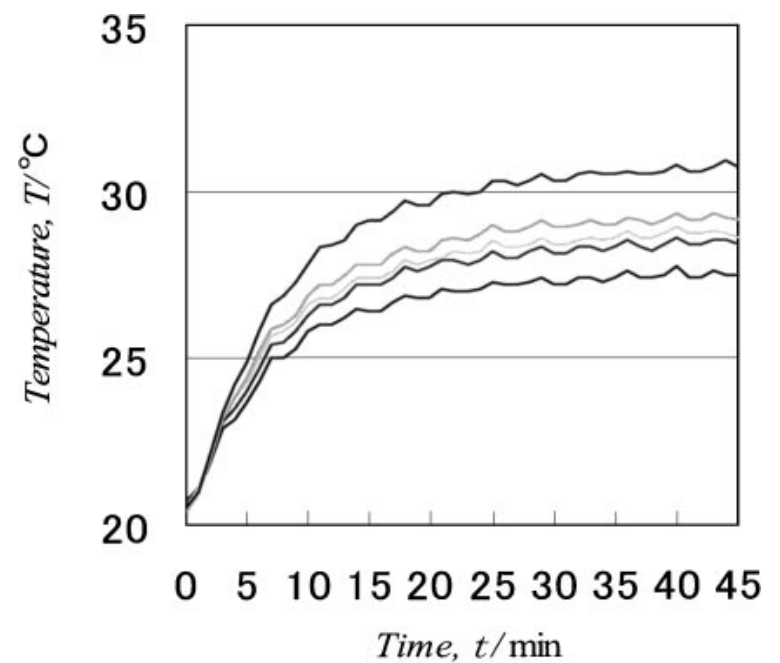

(b)

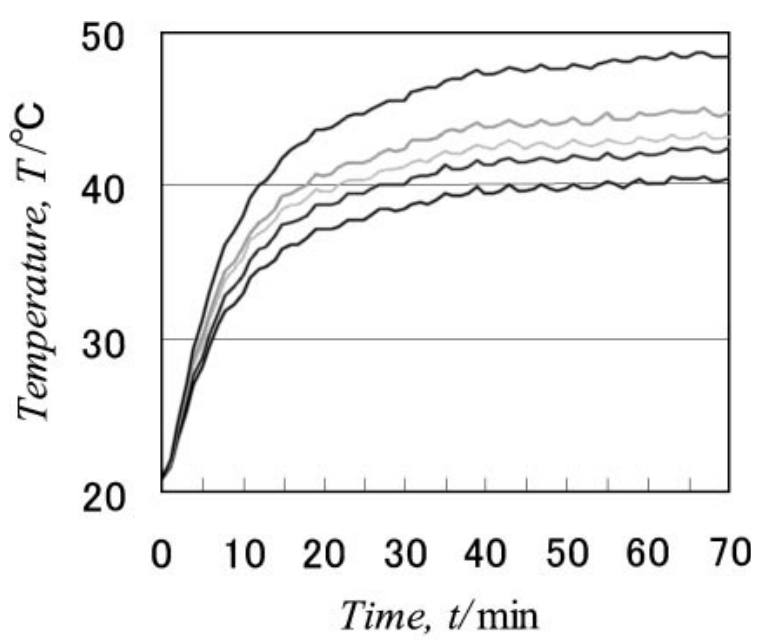

(c)

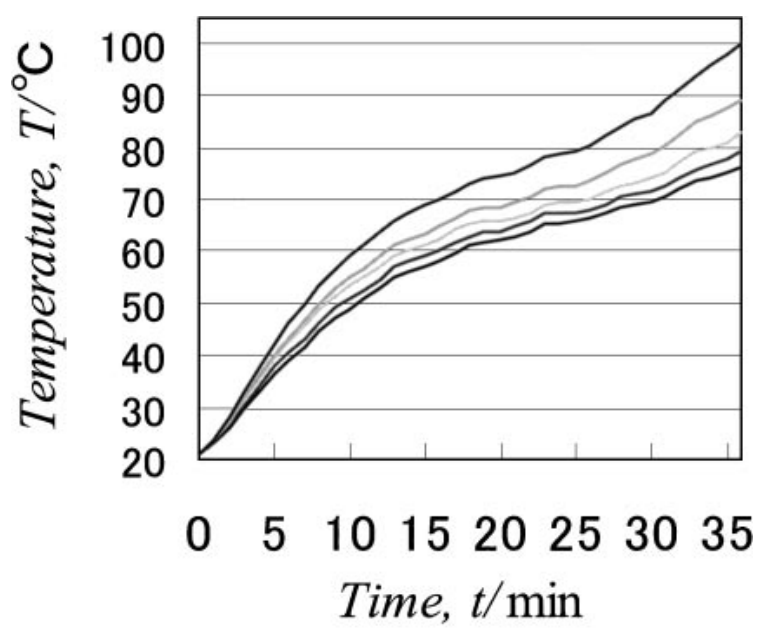

(d)

Fig. 8 (a) Temperature profile for 650 , at $10 \mathrm{~V}$. (b) Temperature profile for 650 , at $20 \mathrm{~V}$. (c) Temperature profile for 650 , at $30 \mathrm{~V}$.

(d) Temperature profile for 650 , at $40 \mathrm{~V}$.

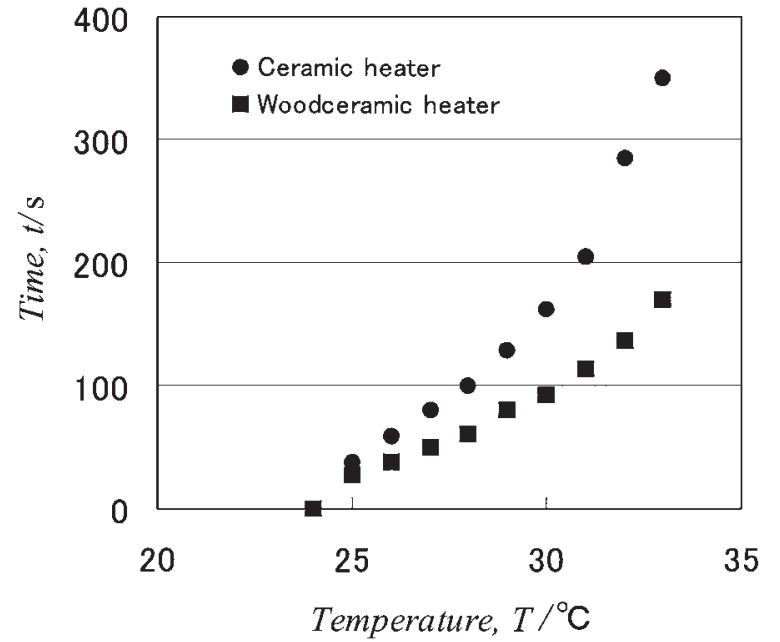

Fig. 9 Temperature vs time profiles of the heater block and conventional ceramic heater. constant applied voltage and current of AC $10 \mathrm{~V}$ and $60 \mathrm{~mA}$. Quick temperature rise under low power input is observed for woodceramic heaters; i.e., woodceramic heaters can attain the required temperature in about half the time necessary for ceramic heaters.

\section{Conclusion}

Woodceramic heating blocks suitable for low temperature heating, e.g., in biological incubator systems, were fabricated by carbonizing medium density fiberboard (MDF) impregnated with phenolic resin. Woodceramic heating blocks having lower water absorptivity were found to be favorably produced by carbonizing in the temperature range of $650-$ $800^{\circ} \mathrm{C}$. Furthermore, by optimizing conditions such as applied voltage and block configuration, it has been found that stable heater operation can be realized by the single use of heater block carbonized at $650^{\circ} \mathrm{C}$; i.e., at $22^{\circ} \mathrm{C}$ under applied voltage of $10 \mathrm{~V}$, and at $27-31^{\circ} \mathrm{C}$ under $20 \mathrm{~V}$. 
The advantages of the woodceramic heaters as compared with the conventional ceramic heaters are as follows: (1) Capable of quickly rising the temperature; (2) High stability at designated temperature; (3) Lower power consumption; and (4) Homogeneous and direct heating of the sample (free of air convection).

\section{REFERENCES}

1) T. Okabe and K. Saito: Jpn. Tokyo Kokai No. 1992-164806.

2) H. Iizuka, M. Fushitani, T. Okabe and K. Saito: J. Porous Mater. 6 (1999)
175-184.

3) K. Saito, K. Hokkirigawa, M. Otsuka, M. Fushitani and T. Okabe (Ed.): Woodceramics (in Japanese), (Uchida Rokakuho Publishing Co. Ltd., Tokyo, Japan, 1996).

4) T. Okabe, T. Hirose, R. Ozao, M. Otsuka, M. Mayuzumi, J. Tuzi, H. Chiba and S. Shibata: Trans. Mater. Res. Soc. Jpn. 29 (2004) 2431-2434.

5) K. Kakishita, S. Asai and T. Suda: Trans. Mater. Res. Soc. Jpn. 28 (2003), 229-232.

6) M. Miki, T. Kikuchi, S. Inada, M. Suzuki and J. Takada: J. Jpn. Soc. Powder Powder Metallurgy 52 (2005) 124-130 (In Japanese).

7) T. Hirose, T. Fujino, T. Fan, H. Endo, T. Okabe and M. Yoshimura: Carbon 40 (2002) 761.

8) A. K. Kercher and D. C. Nagle: Carbon 41 (2003) 15-27. 